\title{
Hooked on Research: A Community Clinician Discovers Primary Care Research
}

\author{
Cyntbia K. Wolff, MD
}

Keywords: Practice-based Research, Primary Care Physicians

Me do research? No way! This was my mantra from medical school forward. I wanted to practice primary care. I wanted to work with people, not lab rats. Then, after residency, I finally found myself in my dream job. I was a Family Doctor in rural America, and I loved it! So... me do research? NO WAY!

Then one day, nearly 20 years ago, a patient came to me with a problem I did not know how to handle. Ok, that happened frequently as a new doctor but somehow this problem hit me differently. This young patient had breast cancer. And now she was pregnant, her first pregnancy. She cried out, "I will never live long enough to raise my baby!" Her mother, sister, and aunt had all died from breast cancer.

I knew her breast cancer was genetic, but beyond that, I knew nothing. My colleagues, including the specialists in my area, provided no additional insights. I began a search for answers and hope for this woman. After a few calls, "Hank," later to be known to me as Dr. Henry Lynch, the father of genetic cancer research ${ }^{1}$ and the Lynch of "Lynch Syndrome," 2 answered the phone. "Sure, I will help you care for this woman."

So began a long relationship where we worked together to find ways to bring the results of his research on genetic breast and colon cancer to my colleagues and to my patients in meaningful ways. But this was just good and exciting family medicine, right? It was not research... or was it?

This article was externally peer reviewed.

Submitted 6 February 2017; revised 11 June 2017; accepted 20 June 2017.

From Floyd Valley Healthcare, Le Mars, IA.

Funding: none.

Conflict of interest: none declared.

Corresponding author: Cynthia K. Wolff, MD, Floyd Valley Healthcare, 714 Lincoln Street NE, Le Mars, IA 51031 (E-mail: Cindie.Wolff@avera.org).
Well, to say I was hooked is an understatement. My interest in genetic cancers led to other opportunities and I began getting invitations to speak about genetic cancers. I learned about Practicebased Research Networks (PBRNs) and joined the statewide practice-based research network known as IRENE (Iowa Research Network) out of the University of Iowa. From time to time researchers from IRENE would ask me to participate in their research projects. Occasionally I did, when I believed it would be helpful to my patients and to my practice, or when it was not overly intrusive.

But I still did not acknowledge that I was engaged in research, because my participation simply involved the gathering of information-from my patients on their preferences, on what worked best for them, and on how they thought medicine might work better to meet their needs. Then we implemented new ways of reaching patients and colleagues with already proven medical information or technologies and looked to see if these were effective. Oh, this was just good family medicine, I thought. This was what I did every day, just now in a way where I collaborated with researchers. Hmm... maybe I did want to do research after all.

Then came radon. In 2012 I had an opportunity to attend the Iowa Cancer Consortium Meeting. Here was a diverse gathering of researchers, clinicians, patients, advocates, policy makers, and stakeholders, all in one place. At one of the presentations I heard about the high levels of radon in Iowa ${ }^{3}$ and about how radon is the leading cause of lung cancer in nonsmokers. ${ }^{4}$ As with genetic breast cancer, this was information that I did not know, that my colleagues did not know, that my patients did not know-and the research and information was solid! I knew immediately that I had to get this information to my community. 
The difference this time, unlike with genetic breast cancer, was that I was sitting next to a researcher who wanted to help, at a meeting filled with people who wanted to help. In 1 week, we had a grant and a research plan to work with the University of Iowa to measure the radon levels in my community, to educate my community on the dangers of radon, and to remedy the radon problem in our homes. My community quickly became engaged, forming committees and speaking teams, coming together to collectively address the radon problem.

Our radon project was a great success! Kits we gave out resulted in 750 people testing their homes for radon, and many more learned and spread the word about the dangers of radon. The University of Iowa learned what the radon numbers were in our area. Until then, these numbers were unknown. They were higher than expected and were used to help change policy. An article was written and published by the University researcher ${ }^{5}$ and the research results were presented at many meetings, including an international research meeting.

Wow, I was only doing what family doctors have always done, seeing a problem in the community and then looking for ways to fix it. The difference was my partnership with a researcher and with a coalition. But that difference took my small efforts to new heights! What my community did suddenly was multiplied 100 times over to help other communities. Not only were my patients helped, but patients across the country and in other countries as well. The radon story went so much farther than I ever could have imagined.

But something else came out of that experience, something I never expected. This was not just a story about how we spread the news of the dangers of radon. This was also a story about how communities can work together with their primary care physicians, researchers and other stakeholders, to solve their real- world health care problems. This was a story about a Triad, a Triad of patients, clinicians, and researchers, and about the power of this Triad to impact problems through collaboration.

I have since learned how PBRNs throughout the United States and Canada are using the power of the Triad to develop collaborative research with primary care clinicians and their patients. And other organizations as well - the Academy of Family Practice through their National Research Network, the North American Primary Care Research Network (NAPCRG), and large funding organizations, like the Patient Centered Outcomes Research Institute.

My pregnant patient with breast cancer, she was the catalyst, she got the ball rolling for me back in the beginning. She went on to deliver and then raise a healthy baby. I went on to establish the Hereditary Cancer Prevention Clinic. And I became passionate about research.

So now what is next? I continue to develop research projects that will benefit my community and my practice, and at the same time will benefit a larger sphere. And I do it by forming Triads: collaborations between patients, clinicians, and researchers.

But I also want to show other clinicians how what they do every day can be translated into something that brings great rewards and excitement to their clinical work, without adding to its burden. Because I do not do all this research work myself. That is the beauty of it. I do what I have always and will always do, I take care of my patients.

But in the course of that work, I see and I learn things. I know what the needs are, what the questions are, and what needs to be answered. And, I know who to call, who to reach out to, who to empower, and who to encourage. I can make the connections needed to get the research work done.

Me do research? Well... I guess I do!

\section{Table 1. Additional Resources}

\footnotetext{
For a good explanation of primary care research, visit: https://youtu.be/pbfYwW8Hlqs

To learn more about NAPCRG, visit: http://www.napcrg.org.

To learn more about the NAPCRG project Patient and Clinician Engagement (PaCE), visit: http://www.napcrg.org/Programs/ Engagement-PACE.

To learn more about Practice-based Research (PBR) Networks, visit the Agency for Healthcare Research and Quality (AHRQ) Centers for Primary Care PBR: https://pbrn.ahrq.gov.

For information on more than 178 PBR Networks registered with the AHRQ PBRN Resource Center, visit the AHRQ PBRN Registry: https://pbrn.ahrq.gov/pbrn-registry.

To learn more about the American Academy of Family Physicians National Research Network, visit: http://www.aafp.org/patientcare/nrn/nrn.html.
} 
I am a practicing family doctor, who was once a research skeptic. But, when I learned that practicebased research could just be part of being a good family doctor, then I became hooked on research, and my practice, my patients, and my community are the better for it.

The author thanks David Wolff, MD for his thoughtful comments on this essay.

To see this article online, please go to: http://jabfm.org/content/ 30/5/678.full.

\section{References}

1. Tribute to Dr. Lynch. Lynch Syndrome International. 2015. Available from: https://lynchcancers. com/lynch-syndrome/tribute-to-dr-lynch. Accessed on June 11, 2017.

2. Sehgal R, Sheahan K, O'Connell PR, et al. Lynch syndrome: An updated review. Genes 2014;5:497507.

3. Breathing easier: An informational radon video for physicians. Iowa Cancer Consortium. 2012. Available from: https://www.youtube.com/watch?v= Fuzl3Nb_ah0. Accessed on June 11, 2017.

4. Field RW, Withers BL. Occupational and environmental causes of lung cancer. Clin Chest Med 2012; 33:681-703.

5. Levy BT, Wolff CK, Niles P, et al. Radon testing: Community engagement by a rural family medicine office. J Am Board Fam Med 2015;28: 617-23. 